\title{
Sensitivity and Specificity of an Electrocardiogram to Detect Echocardiographic Left Ventricular Hypertrophy in a Sample of 326 Tanzanian Adults: Differences in Men and Women
}

Pilly Chillo

Department of Internal Medicine, Muhimbili University of Health and Allied Sciences, Dar es Salaam, Tanzania
Correspondence: Pilly Chillo Department of Internal Medicine, Muhimbili University of Health and Allied Sciences, PO BOX 6500I, Dar es Salaam, Tanzania

Tel +255222150603

Email pchillo2000@yahoo.co.uk
Background: Although an electrocardiogram (ECG) is often used as the only tool to detect left ventricular hypertrophy (LVH) in many out-patient clinics in sub-Saharan Africa (SSA), its sensitivity has been reported to be low especially among black populations, and several studies have reported gender differences. These observations have however not been widely studied among SSA blacks.

Aim: To study the sensitivity and specificity of the ECG in detecting echocardiographic LVH in a sample of native adult Tanzanians.

Methods: Echocardiography and 12-lead resting ECGs were performed in Tanzanian adults who participated in studies to determine the prevalence and functional consequences of abnormal left ventricular geometry in out-patients with hypertension and diabetes. ECGLVH was determined using Sokolow-Lyon (S-L) and Cornell product (C-P) criteria, and compared with echocardiographic LVH.

Results: In total, 326/425 (76.7\%) participants of the original cohort had both ECG and echocardiogram measurements, and were included in this analysis. Echocardiographic LVH was present in $23.7 \%$ and $26.2 \%$ of men and women, respectively, while ECG-LVH was detected by S-L in $36.3 \%$ of men and $17.3 \%$ of women, and by C-P criteria in $20 \%$ of men and in $30.4 \%$ of women. The sensitivity [95\% CI] and specificity [95\% CI] of the S-L criteria was $43.8 \%$ [26.8-62.1\%] and 66.0\% [55.9-74.9\%] in men while it was 36\% [23.3-50.9\%] and $89 \%$ [82.8-93.7\%] in women, respectively. For the C-P criteria, the sensitivity and specificity were $43.8 \%$ [26.8-62.1\%] and $87.4 \%$ [79.0-92.8\%] in men and 60\% [45.2$73.3 \%$ ] and $80.1 \%$ [89.7-97.8\%] in women, respectively.

Conclusion: The sensitivity of the ECG to detect LVH is low in this population, but better than that found in many white populations. Men and women have differences in the sensitivity of the different ECG criteria, with men performing better with S-L and women with C-P criteria. These differences should be considered when including or excluding cases with ECG-LVH in our populations.

Keywords: electrocardiogram, left ventricular hypertrophy, echocardiography, sensitivity, specificity, Tanzania, sub-Saharan Africa

\section{Introduction}

Left ventricular hypertrophy (LVH) is a strong and independent predictor of cardiovascular disease events including myocardial infarction, sudden death, stroke, congestive heart failure and overall CVD mortality. ${ }^{1-7}$ The existence of LVH in 
hypertensive, diabetic or even the general population has therefore important implications for assessing risk and for management with regards to decision making on interventions and/or medications to be used. ${ }^{8}$

LVH has been found to be highly prevalent among hypertensive and diabetic blacks in Africa and in the USA, ${ }^{9-12}$ which could partly explain the increased cardiovascular morbidity and mortality seen in blacks. ${ }^{13,14}$ It is therefore especially important to accurately diagnose LVH in these populations. To date, a number of highly accurate diagnostic tests for LVH detection are available, and they include cardiac magnetic resonance imaging (MRI), computed tomography (CT) - Scan and more recently 3- and 4-dimensional echocardiography. ${ }^{15}$ These tests are however limited by their costs and/or invasiveness, and therefore not recommended for regular clinical use. Two-dimensional trans-thoracic echocardiography is currently the recommended standard diagnostic test for the detection of $\mathrm{LVH}^{8}{ }^{8}$ Despite this, echocardiography is still not available in many parts of sub-Saharan Africa (SSA), ${ }^{16}$ making most clinicians in the region rely on the electrocardiogram (ECG) as the only tool available to diagnose or exclude LVH. However, the ECG has generally been questionable in its ability to detect or refute a true LV mass increase due to its variable sensitivity and specificity, ${ }^{17}$ with gender differences, ${ }^{18,19}$ making it an unreliable test especially among black populations. ${ }^{20,21}$ Furthermore, other factors including age, body habitus, race, underlying condition as well as the ECG criteria used, are known to influence the sensitivity and specificity of the ECG. ${ }^{22}$

Most of the previous studies on ECG among SSA populations have studied the prevalence and factors associated with ECG-LVH. ${ }^{23-26}$ Only few studies from the region have studied the ECG sensitivity and specificity to detect echocardiographic LV mass increase. ${ }^{26-29}$ Furthermore, the gender difference in the sensitivity and specificity of the ECG has not been previously studied. The current study was therefore carried out to determine the sensitivity and specificity of the commonly used ECGLVH criteria, the Sokolow-Lyon (S-L) and the Cornell product (C-P) criteria, and to study gender differences in a sample of native Tanzanian adults.

\section{Methods}

\section{Study Design and Population}

This was a cross-sectional study conducted among untreated hypertensives, diabetic patients and normal individuals who participated in studies that were done to determine prevalence and functional consequences of echocardiographically determined LVH at Muhimbili National Hospital in Dar es Salaam, Tanzania. ${ }^{9,10,30}$ The present analysis include all adult ( $\geq 18$ years) participants for whom an electrocardiogram was also recorded at the time of echocardiogram examination.

\section{Sample Size}

The sample size was calculated using the Kish-Leslie formula and a total of 320 subjects was enough to determine the prevalence of ECG-LVH at a power of $80 \%$, using the previous known prevalence of $16 \%$ in the Tanzanian adult diabetic population. ${ }^{23}$

\section{Data Collection Methods}

\section{Socio-Demographic and Clinical Variables}

Structured questionnaires were used to record the participants' socio-demographic characteristics, cardiovascular risk factors and use of medications. Height, weight, waist and hip circumference were measured. Body mass index was calculated from body weight in kilograms divided by height in $\mathrm{m}^{2}$ and obesity was considered present when body mass index was $\geq 30 \mathrm{~kg} / \mathrm{m}^{2}$. ${ }^{31}$ Waist circumference was considered increased when it was $>88 \mathrm{~cm}$ in women and $>110 \mathrm{~cm}$ in men.

A mercury sphygmomanometer was used to measure blood pressure, and a set of three readings, five minutes apart were performed by an experienced study nurse. For analysis, the average of the last two readings was taken as the participant's clinic blood pressure.

Blood samples were drawn in the morning after an overnight fast and analyzed for creatinine, lipid profile and glucose. Biochemical tests were performed with the use of a chemistry analyser (Abbott Architect, Illinois, USA) at the Muhimbili National Hospital laboratory, while blood glucose was analyzed at the clinic using a HemoCue AB glucose analyzer (Angelholm, Sweden).

\section{Electrocardiography}

All electrocardiograms were performed at the Muhimbili National Hospital Electrocardiogram laboratory using a Phillips Machine. A 12-lead ECG was used and measurements were done in a quiet room by an experienced nurse. All ECGs were interpreted by the primary investigator and proofread by another senior cardiologist. QRS duration was measured to the nearest $4 \mathrm{~ms}$ and the R-wave amplitudes in leads aVL, $\mathrm{V}_{5}$, and $\mathrm{V}_{6}$; and $\mathrm{S}$ wave 
amplitudes in leads $\mathrm{V}_{1}$ and $\mathrm{V}_{3}$ were measured to the nearest $0.5 \mathrm{~mm}(0.05 \mathrm{mV})$ using calipers. The product of QRS duration times the Cornell voltage combination ( $\mathrm{RaVL}+\mathrm{SV}_{3}$, with $8 \mathrm{~mm}$ added in women) was used with a threshold value of $2440 \mathrm{~mm} \times \mathrm{ms}$ to identify LVH in the Cornell product criteria. ${ }^{32}$ Sokolow-Lyon voltage $\left(\mathrm{SV}_{1}+\mathrm{RV}_{5 / 6}\right)>38 \mathrm{~mm}$ was considered to indicate $\mathrm{LVH}$.

\section{Echocardiography}

All echocardiograms were performed by the primary investigator (PC) after receiving special training in echocardiography. A SONOS 7500 Phillips machine equipped with a 3-MHz transducer and second harmonic imaging was used. Quantitative echocardiography was performed following the American Society of Echocardiography guidelines. ${ }^{33} \mathrm{LV}$ mass was calculated using the anatomically validated formula by Devereux. ${ }^{34}$ For this analysis, LV hypertrophy was considered present when LV mass indexed for body surface area exceeded $115 \mathrm{~g} / \mathrm{m}^{2}$ in men and $95 \mathrm{~g} / \mathrm{m}^{2}$ in women. ${ }^{8}$ Relative Wall Thickness was calculated as the ratio of end-diastolic posterior wall thickness to end-diastolic LV internal radius and considered increased if $\geq 0.43$. $^{8}$

\section{Data Handling and Statistical Methods}

Data management and statistical analysis was performed using SPSS for Windows version 21.0 (SPSS Inc., Chicago, Illinois, USA). Data were expressed as mean \pm SD for continuous variables and as percentages for categorical variables. Groups of patients were compared using chisquare test for categorical variables and unpaired Student's $t$-test, as appropriate. Bivariate correlations were assessed by Pearson's correlation coefficient. A two-tailed p-value of $\leq 0.05$ was considered statistically significant.

\section{Ethical Considerations}

The study was performed in accordance with the Helsinki Declaration on studies involving human subjects. Ethical approval was obtained from the Muhimbili University of Health and Allied Sciences' research and publication committee, and all participants signed a written informed consent form before any data were collected.

\section{Results}

Out of the 425 participants of the original cohort, 326 (76.7\%) were eligible for this study and had both ECG and echocardiogram measurements. Table 1 shows the demographic and

Table I Demographic and Clinical Characteristics of the Study Population

\begin{tabular}{|c|c|c|c|}
\hline Characteristics & $\begin{array}{c}\text { Men } \\
n=135\end{array}$ & $\begin{array}{l}\text { Women } \\
n=191\end{array}$ & p-value \\
\hline Age (years) & $49.8 \pm 14.7$ & $49.3 \pm 13.4$ & 0.723 \\
\hline Height $(\mathrm{cm})$ & $167 \pm 8$ & $156 \pm 6$ & $<0.001$ \\
\hline Weight $(\mathrm{kg})$ & $71.8 \pm 15.0$ & $69.5 \pm 14.7$ & 0.169 \\
\hline Body Mass Index $\left(\mathrm{kg} / \mathrm{m}^{2}\right)$ & $25.8 \pm 4.7$ & $28.4 \pm 5.5$ & $<0.001$ \\
\hline Body Surface Area $\left(\mathrm{m}^{2}\right)$ & $1.80 \pm 0.19$ & $1.69 \pm 0.18$ & $<0.001$ \\
\hline Waist circumference $(\mathrm{cm})$ & $91 \pm 13$ & $95 \pm 13$ & 0.011 \\
\hline Pulse rate (beats/min) & $76 \pm 14$ & $79 \pm 14$ & 0.013 \\
\hline Systolic Blood Pressure (mmHg) & $146 \pm 24$ & $147 \pm 27$ & 0.745 \\
\hline Diastolic Blood Pressure (mmHg) & $88 \pm 15$ & $90 \pm 16$ & 0.331 \\
\hline Pulse pressure $(\mathrm{mmHg})$ & $57 \pm 17$ & $56 \pm 17$ & 0.695 \\
\hline Fasting Blood Glucose (mmol/l) & $7.8 \pm 4.4$ & $8.0 \pm 4.1$ & 0.611 \\
\hline Total cholesterol $(\mathrm{mmol} / \mathrm{l})$ & $4.8 \pm 1.1$ & $5.6 \pm 1.5$ & $<0.001$ \\
\hline $\mathrm{HDL}-\mathrm{C}(\mathrm{mmol} / \mathrm{l})$ & $1.1 \pm 0.3$ & $1.2 \pm 0.3$ & 0.002 \\
\hline LDL-C (mmol/l) & $3.4 \pm 1.0$ & $4.0 \pm 1.4$ & $<0.001$ \\
\hline Tryglycerides (mmol/l) & $1.5 \pm 0.8$ & $1.6 \pm 1.2$ & 0.237 \\
\hline Serum Creatinine $(\mu \mathrm{mol} / \mathrm{l})$ & $117 \pm 86$ & $93 \pm 43$ & 0.002 \\
\hline \multicolumn{4}{|l|}{ Groups, n (\%) } \\
\hline Hypertensive & $44(32.6)$ & $76(39.8)$ & 0.096 \\
\hline Diabetic & $59(43.7)$ & $87(45.5)$ & \\
\hline Normal & $32(23.7)$ & $28(14.7)$ & \\
\hline
\end{tabular}

Note: Results are mean \pm SD unless stated otherwise.

Abbreviations: HDL-C, high density lipoprotein cholesterol; LDL-C, low density lipoprotein cholesterol. 
Table 2 Mean Values for Electrocardiographic and Echocardiographic Findings in Men and Women

\begin{tabular}{|c|c|c|c|}
\hline Findings & Men $n=135$ & Women $\mathrm{n}=191$ & p-value \\
\hline \multicolumn{4}{|l|}{ Electrocardiographic } \\
\hline S-amplitude in lead $V_{1}(\mathrm{~mm})$ & $9.7 \pm 4.9$ & $10.4 \pm 4.8$ & 0.213 \\
\hline S-amplitude in lead $V_{3}(\mathrm{~mm})$ & $14.3 \pm 8.1$ & $11.9 \pm 6.8$ & 0.003 \\
\hline R-amplitude in lead aVL (mm) & $6.0 \pm 4.4$ & $5.9 \pm 3.5$ & 0.944 \\
\hline R-amplitude in lead $V_{5}(\mathrm{~mm})$ & $21.0 \pm 8.4$ & $14.8 \pm 6.0$ & $<0.001$ \\
\hline R-amplitude in lead $V_{6}(\mathrm{~mm})$ & $18.0 \pm 7.6$ & $14.3 \pm 5.8$ & $<0.001$ \\
\hline QRS duration (ms) & $88 \pm 14$ & $83 \pm 12$ & $<0.001$ \\
\hline Sum of $S V_{1}+R V_{5}(\mathrm{~mm})$ & $30.7 \pm 10.9$ & $25.2 \pm 8.8$ & $<0.001$ \\
\hline Sum of $S V_{1}+R V_{6}(m m)$ & $27.7 \pm 10.5$ & $24.7 \pm 8.9$ & 0.006 \\
\hline Cornell sum (mm) & $20 \pm 9$ & $18 \pm 8$ & 0.012 \\
\hline Cornell product $(\mathrm{mm} \times \mathrm{ms})$ & $1824 \pm 1056$ & $2139 \pm 775$ & $<0.001$ \\
\hline \multicolumn{4}{|l|}{ Echocardiographic } \\
\hline LV end diastolic diameter $(\mathrm{cm})$ & $4.6 \pm 0.6$ & $4.4 \pm 0.6$ & $<0.001$ \\
\hline Intraventricular Septum in diastole $(\mathrm{cm})$ & $1.16 \pm 0.28$ & $1.11 \pm 0.30$ & 0.116 \\
\hline LV posterior wall in diastole $(\mathrm{cm})$ & $0.97 \pm 0.21$ & $0.92 \pm 0.24$ & 0.060 \\
\hline Relative wall thickness & $0.43 \pm 0.12$ & $0.43 \pm 0.14$ & $0.78 \mathrm{I}$ \\
\hline LV Mass (g) & $180.7 \pm 72.0$ & $152.6 \pm 59.6$ & $<0.001$ \\
\hline LV Mass Index $\left(\mathrm{g} / \mathrm{m}^{2}\right)$ & $100.2 \pm 38.2$ & $90.7 \pm 35.4$ & 0.022 \\
\hline
\end{tabular}

Abbreviation: LV, left ventricular.

Table 3 Clinical and Echocardiographic Correlation Coefficients ( $r$ ) for Sokolow-Lyon and Cornell-Product Indices in Men and Women

\begin{tabular}{|c|c|c|c|c|}
\hline \multirow[t]{2}{*}{ Characteristics } & \multicolumn{2}{|c|}{ Sokolow-Lyon (mm) } & \multicolumn{2}{|c|}{ Cornell Product $(\mathrm{mm} \times \mathrm{ms})$} \\
\hline & Men & Women & Men & Women \\
\hline Clinical & $(r)$ & $(r)$ & $(r)$ & $(r)$ \\
\hline Age (years) & $-0.222 * *$ & $0.069^{\mathrm{ns}}$ & $0.113^{\text {ns }}$ & $0.206 * *$ \\
\hline Height $(\mathrm{cm})$ & $-0.227 * *$ & $-0.209 * *$ & $-0.050^{\text {ns }}$ & $-0.272 * * *$ \\
\hline Weight $(\mathrm{kg})$ & $-0.231 * *$ & $-0.198 * *$ & $0.010^{\mathrm{ns}}$ & $-0.015^{\mathrm{ns}}$ \\
\hline Body Mass Index $\left(\mathrm{kg} / \mathrm{m}^{2}\right)$ & $-0.140^{\mathrm{ns}}$ & $-0.132^{\mathrm{ns}}$ & $0.053^{\text {ns }}$ & $-0.118^{\mathrm{ns}}$ \\
\hline Waist circumference $(\mathrm{cm})$ & $-0.216^{*}$ & $-0.148^{*}$ & $0.064^{\mathrm{ns}}$ & $0.036^{\mathrm{ns}}$ \\
\hline Body Surface Area $\left(\mathrm{m}^{2}\right)$ & $-0.256 * *$ & $-0.223 * *$ & $-0.010^{\text {ns }}$ & $-0.175^{*}$ \\
\hline Systolic Blood Pressure $(\mathrm{mmHg})$ & $0.05 \mathrm{I}^{\mathrm{ns}}$ & $0.324 * * *$ & $0.046^{\mathrm{ns}}$ & $0.397^{* * *}$ \\
\hline Diastolic Blood Pressure (mmHg) & $0.103^{\mathrm{ns}}$ & $0.306 * * *$ & $0.077^{\mathrm{ns}}$ & $0.366 * * *$ \\
\hline Pulse pressure $(\mathrm{mmHg})$ & $-0.017^{\mathrm{ns}}$ & $0.226 * *$ & $-0.002^{\mathrm{ns}}$ & $0.287^{* * *}$ \\
\hline Fasting Blood Sugar (mmol/l) & $-0.012^{\mathrm{ns}}$ & $-0.197 * *$ & $-0.134^{\mathrm{ns}}$ & $-0.079^{\text {ns }}$ \\
\hline Total Cholesterol (mmol/l) & $-0.172^{\mathrm{ns}}$ & $-0.068^{\mathrm{ns}}$ & $-0.17 I^{\mathrm{ns}}$ & $-0.012^{\mathrm{ns}}$ \\
\hline $\mathrm{HDL}-\mathrm{C}(\mathrm{mmol} / \mathrm{l})$ & $-0.112^{\mathrm{ns}}$ & $0.079^{\mathrm{ns}}$ & $-0.156^{\mathrm{ns}}$ & $-0.140^{\mathrm{ns}}$ \\
\hline LDL-C (mmol/l) & $-0.149^{\mathrm{ns}}$ & $-0.035^{\mathrm{ns}}$ & $-0.164^{\mathrm{ns}}$ & $0.018^{\mathrm{ns}}$ \\
\hline Triglycerides (mmol/l) & $-0.068^{\mathrm{ns}}$ & $-0.085^{\mathrm{ns}}$ & $0.03 I^{\mathrm{ns}}$ & $0.029^{\text {ns }}$ \\
\hline Serum Creatinine $(\mu \mathrm{mol} / \mathrm{l})$ & $0.185^{*}$ & $0.24 I^{* *}$ & $0.202^{*}$ & $0.195 * *$ \\
\hline \multicolumn{5}{|l|}{ Echocardiographic } \\
\hline Intraventricular septum in diastole $(\mathrm{cm})$ & $-0.029^{\mathrm{ns}}$ & $0.193^{* *}$ & $0.199 *$ & $0.304 * * *$ \\
\hline LV posterior wall in diastole $(\mathrm{cm})$ & $0.087^{\mathrm{ns}}$ & $0.256 * * *$ & $0.244 * *$ & $0.294 * * *$ \\
\hline Relative wall thickness & $-0.012^{\mathrm{ns}}$ & $0.145^{*}$ & $0.066^{\mathrm{ns}}$ & $0.140^{\mathrm{ns}}$ \\
\hline LV end diastolic diameter $(\mathrm{cm})$ & $0.179 *$ & $0.153^{*}$ & $0.247 * *$ & $0.275 * * *$ \\
\hline $\mathrm{LV}$ mass $(\mathrm{g})$ & $0.136^{\mathrm{ns}}$ & $0.325 * * *$ & $0.35 I^{* * *}$ & $0.466 * * *$ \\
\hline $\mathrm{LV}$ mass index $\left(\mathrm{g} / \mathrm{m}^{2}\right)$ & $0.220 * *$ & $0.400 * * *$ & $0.374 * * *$ & $0.534 * * *$ \\
\hline
\end{tabular}

Abbreviations: HDL-C, high density lipoprotein cholesterol; LDL-C, low density lipoprotein cholesterol; LV, left ventricular *, ** and $* * *$ denotes significant levels at $\mathrm{p}<$ $0.05,<0.01$ and $<0.001$, respectively. ns, not significant. 


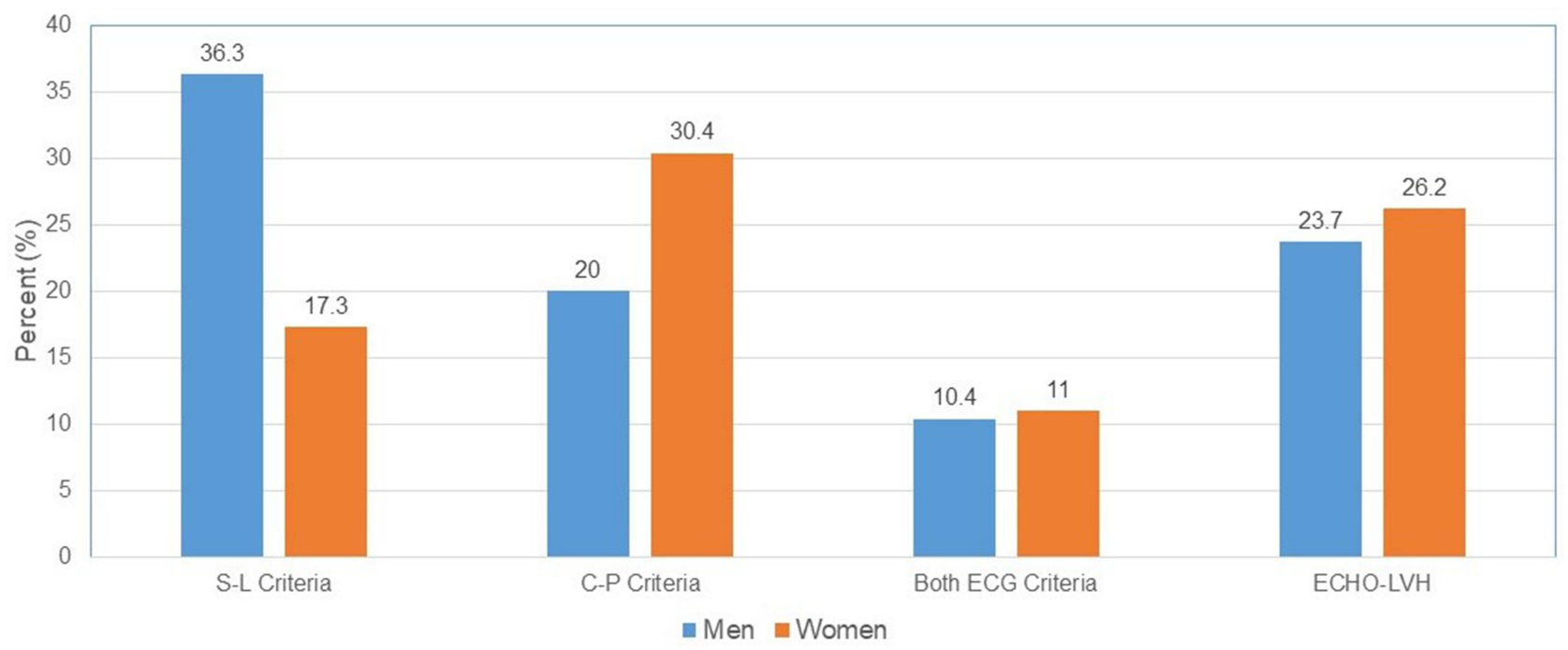

Figure I Prevalence of electro- and echo-cardiographic LVH in men and women.

clinical characteristics in men and women. The mean (SD) age of the total population was 49.5 (13.9) years (range 18-85), and $58.6 \%$ were women. On average, men were taller, leaner

\section{Men}
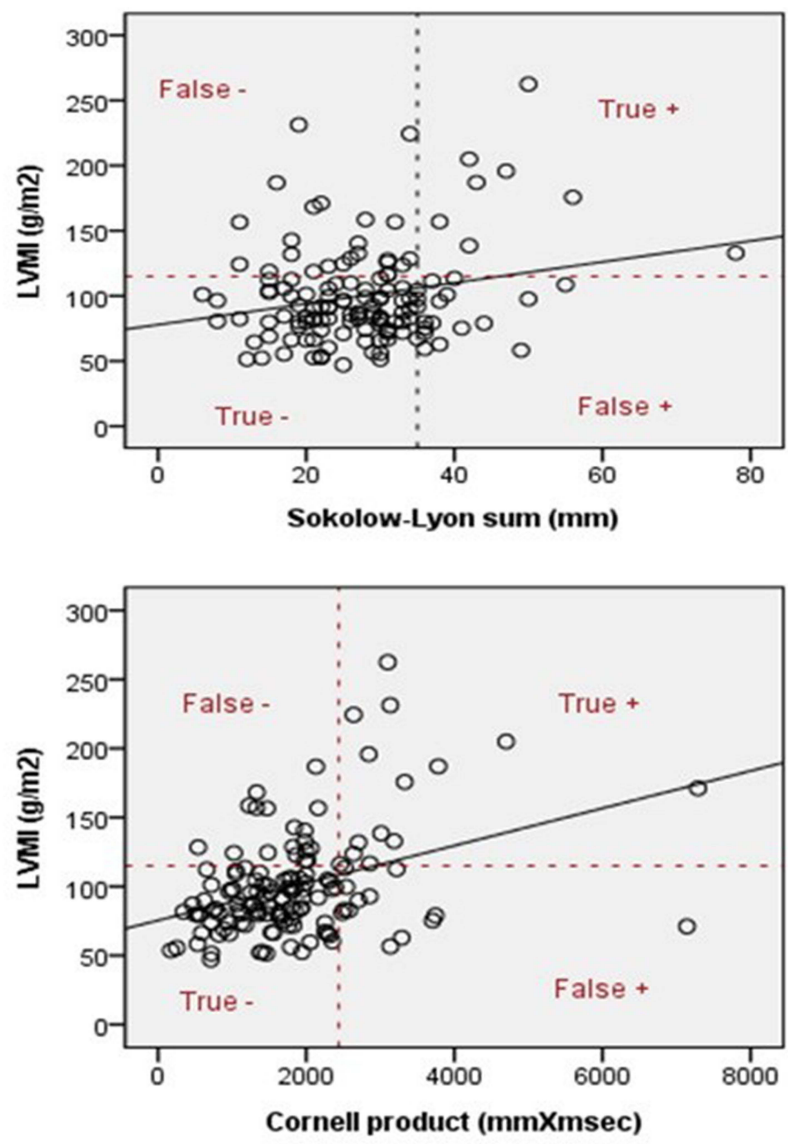

and had higher serum creatinine levels when compared with women. Women had higher mean values for overweight and an unfavourable lipid profile.
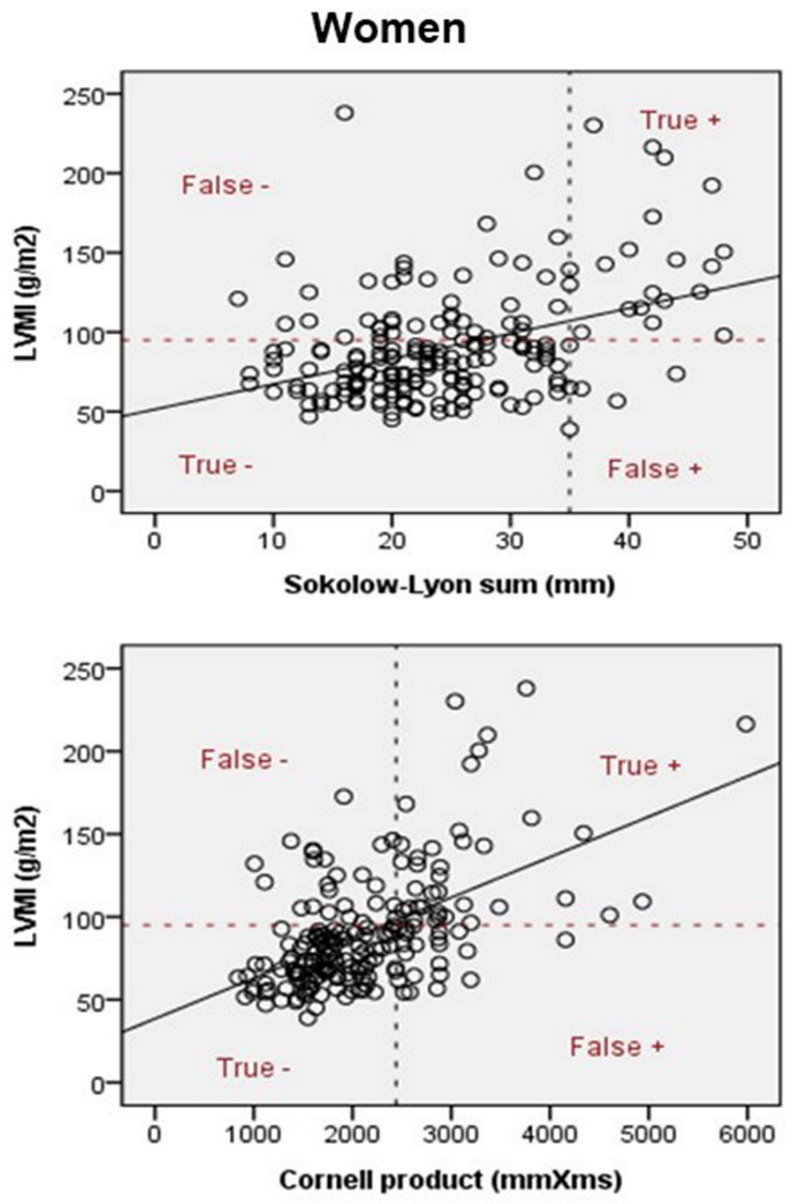

Figure 2 Correlation between the S-L and C-P indices with echocardiographic LV mass index. 
Table 4 Sensitivity and Specificity of the ECG in Detecting Echocardiographic LVH in Men and Women

\begin{tabular}{|c|c|c|c|c|}
\hline \multirow[t]{2}{*}{ ECG - Criteria } & \multicolumn{2}{|c|}{ Men } & \multicolumn{2}{|c|}{ Women } \\
\hline & Sensitivity & Specificity & Sensitivity & Specificity \\
\hline Sokolow-Lyon & $43.8 \%(14 / 32 * 100)$ & $66.0 \%(68 / 103 * 100)$ & $36.0 \%(18 / 50 * 100)$ & $89 \%(126 /|4| * \mid 00)$ \\
\hline Confidence Interval & {$[26.8-62.1]$} & [55.9-74.9] & {$[23.3-50.9]$} & [82.8-93.7] \\
\hline Cornell-Product & $43.8 \%(14 / 32 * 100)$ & $87.4 \%(90 / 103 * 100)$ & $60.0 \%(30 / 50 * 100)$ & $80.1 \%(1|13 / 14| * 100)$ \\
\hline Confidence Interval & {$[26.8-62.1]$} & [79.0-92.8] & [45.2-73.3] & [72.4-86.2] \\
\hline Both Criteria & $28.1 \%(9 / 32 * 100)$ & $95.1 \%(98 / 103 * 100)$ & $28.0 \%(14 / 50 * 100)$ & $95.0 \%(134 / 14 \mid * 100)$ \\
\hline Confidence Interval & [14.4-46.9] & [88.5-98.2] & {$[16.7-42.7]$} & [89.7-97.8] \\
\hline
\end{tabular}

Table 2 shows the mean values for electrocardiographic and echocardiographic findings compared between men and women. Most of the electrocardiographic findings differed between men and women, with men having significantly higher mean values of chest leads voltages, as well as higher mean QRS duration, all $\mathrm{p}<0.01$. On the other hand, women had significantly higher mean value for the C-P criteria $(\mathrm{p}<0.001)$. On echocardiography, men had significantly higher mean values for LV end diastolic diameter, higher LV mass and LV mass index, all $\mathrm{p}<0.05$.

Table 3 shows the correlation between clinical and echocardiographic parameters with sum of voltage (as a function of S-L criteria) and the total Cornell-product index (as a function of C-P criteria). For the S-L criteria men had best correlations between leanness parameters and the sum of S-L, but no significant correlations with blood pressure. On the other hand, women in addition to measures of leanness, had also significant correlations between S-L and blood pressure. In men, only serum creatinine correlated with the C-P criteria, while several factors including age, blood pressure as well as serum creatinine showed significant correlations in women.

LV mass index had significant correlation with both ECG LVH criteria in men and women, although women had better correlation coefficients in both criteria (Table 3 ).

The prevalence of LVH by electrocardiogram and echocardiogram is shown in Figure 1. In those diagnosed to have ECG-LVH, only $10.4 \%$ and $11 \%$ of men and women respectively were diagnosed by both the S-L and C-P criteria.

The correlation between LV mass index with the $\mathrm{S}-\mathrm{L}$ and C-P indices as continuous variables is shown in Figure 2. Both criteria had significant and positive correlations with LV mass index as shown in the figure. Inserting the defining variables for LVH, Figure 2 shows the ability of the ECG to detect true LV mass increase as detected by echocardiography. Repeating this analysis using LV mass indexed for height ${ }^{2.7}$ did not much alter the correlations and the sensitivity results.

As shown in Table 4, the sensitivity and specificity of the two ECG criteria differed between men and women, with women having best sensitivity and specificity using the C-P criteria, while men had equal sensitivity using the $\mathrm{S}-\mathrm{L}$ criteria, and the overall poorest specificity when the S-L criteria was used. Of note, when both criteria were used, the sensitivity dropped to $28 \%$ but with a higher specificity at $95 \%$ for both men and women (Table 4 ).

\section{Discussion}

Accurate diagnosis of LVH is important for clinical decision making. The cheap and readily available ECG has traditionally been the mainstay screening tool, however there are increasing concerns that the ECG is problematic in detecting true LVH. ${ }^{35}$ The present study confirms, and adds to the current literature among sub-Saharan black populations that the commonly used criteria S-L and C-P have low sensitivity in a native Tanzanian population, nonetheless with high specificity in detecting echocardiographic LVH. Further, there are ECG differences between men and women.

Both ECG criteria used for LVH diagnosis in this study had low sensitivity regardless of gender, similar to previous studies in Africa ${ }^{26,28,29}$ and from other parts of the world. ${ }^{17,18,20,21,36}$ The sensitivity seen in this study is however relatively higher than that obtained from several studies among white populations. $^{17,20,37,38}$ In a recent publication from the Netherlands, de Hartog-Keyzer and colleagues reported the ECG to be only $14 \%$ sensitive in detecting echocardiographic LVH in a population of patients with long-standing hypertension, ${ }^{17}$ while in the Losartan Intervention For Endpoint reduction (LIFE) study the sensitivity among white patients was $27 \%$ and $45 \%$ when the S-L and C-P criteria were used, respectively. ${ }^{20}$ In a meta-analysis performed by Pewsner et al. which included mainly white populations in Europe and 
America, the sensitivity reported ranged between $8.5-21 \%$, again much lower than the findings using either of the ECG criteria in the current study of black native Tanzanians. Nevertheless, our results show that the ECG only detected a few (between 36-60\%) of the participants with echocardiographic LVH, leaving many others as false negatives. In clinical practice, this is unfavorable since patients with $\mathrm{LVH}$ need special attention in terms of medications choice and risk stratification, therefore a more sensitive test would be best. Others have suggested that the ECG should not be used to detect LVH due to its low and unreliable sensitivity. ${ }^{38}$ However, previous studies have found LVH detected by ECG provides independent prognostication of cardiovascular events, ${ }^{2,39}$ and this has been attributed to other mediation of prognosis including genetic differences seen in electrocardiographic $\mathrm{LVH}^{40}$ It is therefore sensible to note that the ECG remains a valuable test in clinical cardiology.

Apart from the S-L in men, the other ECG criteria in this study had high specificity ranging from $80-89 \%$, meaning that the ECG in this aspect was good in detecting patients without LVH. This finding has been reported by others $^{17,18,20,26,28,36}$ and it is generally known that the ECG is mostly highly specific. ${ }^{35}$ In the LIFE study which included both black and white hypertensives in Europe and America, using the S-L criteria, the ECG was less specific among blacks (44\%) when compared with whites $(69 \%)$ in that study. ${ }^{20}$ The findings in this study show a relatively higher specificity even with the S-L criteria, and suggest that the lower specificity observed among blacks compared with whites in the LIFE study was likely due to the low specificity in men and not in women, as seen in this study (Table 4). However, in a setting of low sensitivity, the high specificity does not make sensible clinical meaning since many patients with $\mathrm{LVH}$ are, to begin with, labeled as without LVH. In this study, the specificity reached $95 \%$ when both criteria were positive for $\mathrm{LVH}$, but at a very low sensitivity of $28 \%$. Of note only $10.4 \%$ of women and $11 \%$ of men participants in our study were detected by both criteria, confirming the general observation that patients who meet one set of ECG criteria for LVH commonly do not meet other criteria. ${ }^{35}$ Okin et al. found that only $11.2 \%$ of patients with LVH by either Cornell voltage criteria or Sokolow-Lyon criteria had LVH diagnosed by both criteria in a large multiracial sample of patients with hypertension, ${ }^{32}$ remarkably similar to the present study.

Men and women differ in terms of their body habitus as well as cardiac muscle mass, with different ECG criteria giving different sensitivity and specificity between men and women. ${ }^{35}$ In the present study, using the S-L, men compared with women had better sensitivity $(43.8 \%$ versus $30 \%)$, but at a cost of lower specificity (66\% versus $89 \%)$. While women performed better with the C-P criteria reaching a sensitivity of $60 \%$ (versus 43.8\%). These differences between men and women are similar to previous reports from outside SSA, ${ }^{2,18,36,41}$ and our study confirms this observation also in a native black population from Tanzania. Of note, in this study the clinical and echocardiographic parameters correlated better with the C-P criteria in women (Table 3 ) indicating a true relationship between the increased C-P indices with clinical and echocardiographic parameters. On the other hand, the S-L being calculated from chest leads, favored men due to the fact that the chest leads are in close proximity with the heart, different from women (due to the breast tissue), as others have suggested. $^{36,41}$ Of note, men had significantly higher mean values for chest leads V3 - V6, compared with women (Table 2), and these are likely to translate to higher S-L indices, and therefore higher sensitivity to detect $\mathrm{LVH}$, although at a cost of low specificity. It is also seen in our findings that among men, the S-L index did not correlate with important clinical variables for LVH including blood pressure, indicating a lack of relationship between the two (Table 3). This has translated to the lowest ECG-LVH specificity in this study $(60 \%)$, also confirming previous other studies. $^{21,36,41}$

This study is among the first to study the sensitivity and specificity of ECG in detecting echocardiographic LVH in Tanzania, therefore the study provides baseline data for future comparisons.

\section{Conclusion}

The sensitivity of the ECG to detect LVH is low in this population, comparable to previous observations but better than that found in many white populations. Men and women have differences in the sensitivity of the S-L and C-P criteria, with men performing better with S-L and women with C-P criteria. These differences should be considered when including or excluding cases with ECG-LVH among our populations.

\section{Disclosure}

The author reports no conflicts of interest in this work. 


\section{References}

1. Sundstrom J, Lind L, Arnlov J, Zethelius B, Andren B, Lithell HO. Echocardiographic and electrocardiographic diagnoses of left ventricular hypertrophy predict mortality independently of each other in a population of elderly men. Circulation. 2001;103(19):2346-2351. doi:10.1161/01.CIR.103.19.2346

2. Okwuosa TM, Soliman EZ, Lopez F, Williams KA, Alonso A, Ferdinand KC. Left ventricular hypertrophy and cardiovascular disease risk prediction and reclassification in blacks and whites: the Atherosclerosis Risk in Communities Study. Am Heart J. 2015;169 (1):155-161 e155. doi:10.1016/j.ahj.2014.09.013

3. Bots ML, Nikitin Y, Salonen JT, et al. Left ventricular hypertrophy and risk of fatal and non-fatal stroke. EUROSTROKE: a collaborative study among research centres in Europe. $J$ Epidemiol Community Health. 2002;56(Suppl 1):i8-13. doi:10.1136/jech.56.suppl_1.i8

4. Tin LL, Beevers DG, Lip GY. Hypertension, left ventricular hypertrophy, and sudden death. Curr Cardiol Rep. 2002;4(6):449-457. doi:10.1007/s11886-002-0105-6

5. Walker RW, Dewhurst M, Gray WK, et al. Electrocardiographic assessment of coronary artery disease and stroke risk factors in rural and urban Tanzania: a case-control study. $J$ Stroke Cerebrovascular Dis. 2014;23(2):315-320.

6. Lang RM, Badano LP, Mor-Avi V, et al. Recommendations for cardiac chamber quantification by echocardiography in adults: an update from the American Society of Echocardiography and the European Association of Cardiovascular Imaging. Eur Heart $J$ Cardiovasc Imaging. 2015;16(3):233-270.

7. Chillo P, Lwakatare J, Rieck AE, Lutale J, Gerdts E. Prevalence and covariates of abnormal left ventricular geometry in never-treated hypertensive patients in Tanzania. Blood Press. 2014;23(1):31-38. doi:10.3109/08037051.2013.791415

8. Chillo P, Lwakatare J, Lutale J, Gerdts E. Increased relative wall thickness is a marker of subclinical cardiac target-organ damage in African diabetic patients. Cardiovasc J Afr. 2012;23(8):435-441. doi:10.5830/CVJA-2012-023

9. Baldo MP, Goncalves MA, Capingana DP, Magalhaes P, da Silva ABT, Mill JG. Prevalence and Clinical Correlates of Left Ventricular Hypertrophy in Black Africans. High Blood Pressure Cardiovascular Prevent. 2018;25(3):283-289. doi:10.1007/s40292018-0267-y

10. Ogah OS, Bamgboye AE. Correlates of left ventricular mass in hypertensive Nigerians: an echocardiographic study. Cardiovasc $J$ Afr. 2010;21(2):79-85.

11. Tajeu GS, Safford MM, Howard G, et al. Black-White Differences in Cardiovascular Disease Mortality: a Prospective US Study, 20032017. Am J Public Health. 2020;110(5):696-703. doi:10.2105/ AJPH.2019.305543

12. Yuyun MF, Sliwa K, Kengne AP, Mocumbi AO, Bukhman G. Cardiovascular Diseases in Sub-Saharan Africa Compared to High-Income Countries: an Epidemiological Perspective. Glob Heart. 2020;15(1):15. doi:10.5334/gh.403

13. Agabiti-Rosei E, Muiesan ML, Salvetti M. New approaches to the assessment of left ventricular hypertrophy. Ther Adv Cardiovasc Dis. 2007;1(2):119-128. doi:10.1177/1753944707086350

14. Glezeva N, Gallagher J, Ledwidge $M$, et al. Heart failure in sub-Saharan Africa: review of the aetiology of heart failure and the role of point-of-care biomarker diagnostics. Tropical Med Int Health. 2015;20(5):581-588. doi:10.1111/tmi.12461

15. de Hartog-keyzer JML, El Messaoudi S, Harskamp R, et al. Electrocardiography for the detection of left ventricular hypertrophy in an elderly population with long-standing hypertension in primary care: a secondary analysis of the CHELLO cohort study. BMJ Open. 2020;10(8):e038824. doi:10.1136/bmjopen-2020-038824
16. Gasperin CA, Germiniani H, Facin CR, Souza AM, Cunha CL. An analysis of electrocardiographic criteria for determining left ventricular hypertrophy. Arq Bras Cardiol. 2002;78(1):59-82. doi:10.1590/ S0066-782X2002000100006

17. Goncalves MAA, Pedro JM, Silva C, Magalhaes P, Brito M. Normal limits of the electrocardiogram in Angolans. $J$ Electrocardiol. 2020;63:68-74. doi:10.1016/j.jelectrocard.2020.10.011

18. Okin PM, Wright JT, Nieminen MS, et al. Ethnic differences in electrocardiographic criteria for left ventricular hypertrophy: the LIFE study. Losartan Intervention For Endpoint. Am J Hypertens. 2002;15(8):663-671. doi:10.1016/S0895-7061(02)02945-X

19. Mahn JJ, Dubey E, Brody A, et al. Test characteristics of electrocardiography for detection of left ventricular hypertrophy in asymptomatic emergency department patients with hypertension. Acad Emergency Med. 2014;21(9):996-1002. doi:10.1111/acem.12462

20. Petersen SS, Pedersen LR, Pareek M, et al. Factors associated with diagnostic discrepancy for left ventricular hypertrophy between electrocardiography and echocardiography. Blood Press. 2017;26 (1):54-63. doi:10.1080/08037051.2016.1235959

21. Lutale JJ, Thordarson H, Gulam-Abbas Z, Vetvik K, Gerdts E. Prevalence and covariates of electrocardiographic left ventricular hypertrophy in diabetic patients in Tanzania. Cardiovasc $J$ Afr. 2008;19(1):8-14.

22. Dzudie A, Choukem SP, Dehayem MY, Kengne AP. Blood pressure variables and prevalent electrocardiographic left ventricular hypertrophy in sub-Saharan African individuals with type 2 diabetes. J Diabetes. 2012;4(4):424 431. doi:10.1111/j.1753-0407.2012.00209.x

23. Huston SL, Bunker CH, Ukoli FA, Rautaharju PM, Kuller LH. Electrocardiographic left ventricular hypertrophy by five criteria among civil servants in Benin City, Nigeria: prevalence and correlates. Int J Cardiol. 1999;70(1):1-14. doi:10.1016/S01675273(99)00061-3

24. Dada A, Adebiyi AA, Aje A, Oladapo OO, Falase AO. Standard electrocardiographic criteria for left ventricular hypertrophy in Nigerian hypertensives. Ethn Dis. 2005;15(4):578-584.

25. Mbaye A, Dodo B, Ngaide AA, et al. Left ventricular hypertrophy in black African subjects with artery hypertension: results of a cross-sectional survey conducted in semi-rural area in Senegal. Ann de cardiologie et d'angeiologie. 2017;66(4):210-216. doi:10.1016/j. ancard.2017.04.011

26. Jingi AM, Noubiap JJ, Kamdem P, Kingue S. Determinants and improvement of electrocardiographic diagnosis of left ventricular hypertrophy in a black African population. PLoS One. 2014;9(5): e96783. doi:10.1371/journal.pone.0096783

27. Robinson C, Woodiwiss AJ, Libhaber CD, Norton GR. Novel Approach to the Detection of Left Ventricular Hypertrophy Using Body Mass Index-Corrected Electrocardiographic Voltage Criteria in a Group of African Ancestry. Clin Cardiol. 2016;39(9):524-530. doi: $10.1002 / \mathrm{clc} .22560$

28. Chillo P, Rieck AE, Lwakatare J, Lutale J, Gerdts E. Left atrial volume index as a marker of left ventricular diastolic dysfunction in asymptomatic Tanzanian diabetic patients. Blood Press. 2013;22 (2):86-93. doi:10.3109/08037051.2012.707351

29. National Institutes of Health. Clinical Guidelines on the Identification, Evaluation, and Treatment of Overweight and Obesity in Adults--The Evidence Report. Obes Res. 1998;6(Suppl 2):51S-209S.

30. Okin PM, Devereux RB, Jern S, Kjeldsen SE, Julius S, Dahlof B. Baseline characteristics in relation to electrocardiographic left ventricular hypertrophy in hypertensive patients: the Losartan intervention for endpoint reduction (LIFE) in hypertension study. The Life Study Investigators. Hypertension. 2000;36(5):766-773. doi:10.1161/ 01.HYP.36.5.766

31. Lang RM, Bierig M, Devereux RB, et al. Recommendations for chamber quantification. Eur $J$ Echocardiogr. 2006;7(2):79-108. doi:10.1016/j.euje.2005.12.014 
32. Devereux RB, Alonso DR, Lutas EM, et al. Echocardiographic assessment of left ventricular hypertrophy: comparison to necropsy findings. Am J Cardiol. 1986;57(6):450-458. doi:10.1016/00029149(86)90771-X

33. Bang CN, Soliman EZ, Simpson LM, et al. Electrocardiographic Left Ventricular Hypertrophy Predicts Cardiovascular Morbidity and Mortality in Hypertensive Patients: the ALLHAT Study. Am J Hypertens. 2017;30(9):914-922. doi:10.1093/ajh/hpx067

34. Liao Y, Cooper RS, Durazo-Arvizu R, Mensah GA, Ghali JK. Prediction of mortality risk by different methods of indexation for left ventricular mass. J Am Coll Cardiol. 1997;29(3):641-647. doi:10.1016/S0735-1097(96)00552-9

35. Hancock EW, Deal BJ, Mirvis DM, et al. AHA/ACCF/HRS recommendations for the standardization and interpretation of the electrocardiogram: part V: electrocardiogram changes associated with cardiac chamber hypertrophy: a scientific statement from the American Heart Association Electrocardiography and Arrhythmias Committee, Council on Clinical Cardiology; the American College of Cardiology Foundation; and the Heart Rhythm Society: endorsed by the International Society for Computerized Electrocardiology. Circulation. 2009;119(10):e251-261. doi:10.1161/CIRCULATIO NAHA.108.191097

36. Okin PM, Roman MJ, Devereux RB, Kligfield P. Gender differences and the electrocardiogram in left ventricular hypertrophy. Hypertension. 1995;25(2):242-249. doi:10.1161/01.HYP.25.2.242
37. Levy D, Labib SB, Anderson KM, Christiansen JC, Kannel WB, Castelli WP. Determinants of sensitivity and specificity of electrocardiographic criteria for left ventricular hypertrophy. Circulation. 1990;81(3):815-820. doi:10.1161/01.CIR.81.3.815

38. Pewsner D, Juni P, Egger M, Battaglia M, Sundstrom J, Bachmann LM. Accuracy of electrocardiography in diagnosis of left ventricular hypertrophy in arterial hypertension: systematic review. BMJ. 2007;335(7622):711. doi:10.1136/bmj.39276.636354. $\mathrm{AE}$

39. Okin PM, Hille DA, Kjeldsen SE, Devereux RB. Combining ECG Criteria for Left Ventricular Hypertrophy Improves Risk Prediction in Patients With Hypertension. J Am Heart Assoc. 2017;6(11). doi:10.1161/JAHA.117.007564

40. Mayosi BM, Avery PJ, Farrall M, Keavney B, Watkins H. Genomewide linkage analysis of electrocardiographic and echocardiographic left ventricular hypertrophy in families with hypertension. Eur Heart J. 2008;29(4):525-530. doi:10.1093/eurheartj/ehn028

41. Colossimo AP, Costa Fde A, Riera AR, et al. Electrocardiogram sensitivity in left ventricular hypertrophy according to gender and cardiac mass. Arq Bras Cardiol. 2011;97(3):225-231. doi:10.1590/ S0066-782X2011005000085

\section{Publish your work in this journal}

Research Reports in Clinical Cardiology is an international, peerreviewed, open access journal publishing original research, reports, editorials, reviews and commentaries on all areas of cardiology in the clinic and laboratory. The manuscript management system is completely online and includes a very quick and fair peer-review system. Visit http://www.dovepress.com/testimonials.php to read real quotes from published authors.

Submit your manuscript here: http://www.dovepress.com/research-reports-in-clinical-cardiology-journal 